different Records, as one is requested to at present. The sale of such a work would be greater than that of the present incomplete and tardy publications. Besides, the promoters would doubtless be prepared to sell the various sections separatelyan urgent reform that has long been clamoured for in vain ; this alone would materially increase the receipts.

Having thought much of this subject during the last five years, and having talked it over with many Recorders and bibliographers, I venture to take this opportunity of putting forward the crude outlines of an undeveloped scheme. 'There is no wish to offend those unselfish toilers who have done and are doing so much for us, or the corporate bodies that support them. But this is a question that must be approached from a cosmopolitan standpoint. Men of science all the world over should support it with purse and person. All petty considerations of nationality, even of language, should be sunk. The aim of the work should be the advancement of science ; only if it is truly International, can it possibly be realized out of Utopia.

British Museum (Nat. Hist.), August I9.

PERHAPS you will kindly allow me, as the author of a certain pamphlet on "The Organization of Science," to say a few words on Mr. Minchin's letter (NATURE, August I8), which naturally had an especial interest for me. I am sorrowfully pleased to find the principles advocated in my pamphlet illustrated so well by concrete instance, and, needless to say, I heartily wish Mr. Minchin success in his endeavour to introduce order into at least one province of the scientific class, seeing that the text of my pamphlet may be exactly summed up in his remark-"A great need is the intelligent or anization of scientific research."

One point in Mr. Minchin's letter was of especial interest to me, for he invites the Royal Society to take in hand this work of organization, instead of leaving private individuals to execute at a great sacrifice the work which this wealthy corporation systematically neglects. Now a reference to my pamphlet (pp. II-I4) will show that this was a main thesis sustained there. Whether Mr. Minchin has done me the honour to read my pamphlet and is already preaching my crusade for me, or whether the similarity between our views is a simple coincidence of opinion, I know not, but whichever be the case, it is peculiarly gratifying to me to receive practically an endorsement from one whose experience renders him so especially qualified to speak with authority.

London, August 23.

\section{"The Limits of Animal Intelligence."}

MR. Dixon has not, I think, quite grasped the main tendency of my paper read before the International Congress of Experimental Psychology. Nor is this to be wondered at. $\mathrm{He}$ quotes from a brief summary of what was itself but an abstract of a portion of a work on Comparative Psychology on which I am engaged. I am in agreement with nearly all that Mr. Dixon says, except where he misunderstands my position, and except in the opinion he expresses in the last sentence. When Mr. Dixon says, "Of course it is true that my knowledge of my ozen psychology does differ in kind from my knowledge of that of animals, but it differs in exactly the same way from that of all other men," he is expressing the views which I, in common with most men who have seriously studied the question, hold. And when he says, "If in no case is "an animal activity to be interpreted as the outcome of the exercise of a higher psychical faculty if it can be fairly interpreted as the outcome of one which stands lower in the psychological scale, the same rule should be applied to the (scientific) interpretation of human activities," I can only say that I heartily agree with him. Since, therefore, we have so much in common, I do not propose to occupy valu. able space in discussing the outstanding points of difference between us. I may perhaps be allowed, however, to take advantage of the courtesy of the Editor of NATURE, and to say a few words in elucidation of the thesis I very imperfectly set forth in my paper, a thesis based entirely on observation and induction.

In the first place the study of my own mental processes, and of the nature and sequence of my own states of consciousness, has led me to the conclusion that there is a great difference between the mere feeling or awareness of certain relationships and the clear cognizing of these or other relationships. When I am bicycling, or playing tennis, or when I am living the practical life of naive perception, I am aware of, and shape my actions in accordance with, a feeling of the relations which the objects of the external world bear 10 me and to each other. The greater part of my practical skill in action and of such intelligence as I show in meting the emergencies that occur in my active life, are the outcome of this awareness of relations. But when I begin to attempt to explain phenomena, and to formulate my knowledge of the world, I find I am forced to pay special attention to these relationships as such, and to clearly and precisely cognize them. This conclusion, I repeat, is the outcome of observation, and is not, so far as I am aware, the result of any a priori considerations.

Looking back upon my own past, and collating the results with those reached by other observers, I find that the mere feeling or awareness of relations is prior in development to the clear and precise cognition of them. The awareness of relations seems to be, in fact, the undifferentiated germ from which their clear cognition has been developed; it is not knowledge, properly so called, but it is the raw material from which knowledge and the products of the intellect are shaped. Hence I conclude that the order of development or evolution in man is-first, the practical awareness of relations among phenomena, and then subsequently the cognition and clear knowledge (in the full sense of the word) of these relations as such.

Now, passing to the psychology of animals, such as the higher mammalia, the hypothesis suggests itself that they are still in the stage of mere awareness, and have not reached the stage of clear cognition, which, as I showed in my paper, involves reflection and introspection. This is put forward as an hypothesis; one based on observation and the doctrine of evolution; and one to be treated in the same spirit and on the same methods as other scientific hypotheses. It must be submitted to the iouchstone of verification. The question is :-Are the activities of animals explicable on the supposition that the agents are merely aware of the relations; or must we suppose that they fully cognize them? I feel sure that my own practical activities are in the main based on awareness, and this leads me to suspect that the practical activities of animals are also of like psychological implication. The matter must, however, so far as is possible, be put to the test of experiment and observation. I have conducted from time to time experiments with the object of ascertaining how far there is evidence in the dog of true cognition-of causation for example. I am inclined to believe as the result of my observations that there is nothing beyond a simple awareness of the causal nexus. But $I$ am far from wishing to dogmatize in the matter. I am chiefly concerned that the phenomena should be carefully observed, and that experiments should be conducted ont definite scientific lines.

In conclusion I must be allowed to say that the phrases "difference in kind" and "difference of degree" savour somewhat of mere academic discussion, and may perhaps be left for tho:e who deal with the matter on a priori lines and not from the standpoint of evolution. I for one do not for a moment question that the mental processes of man and of animals are alike products of evolution. The power of cognizing relations, reflection and introspection, appear to me to mark a new departure in evolution. But whether, as I am at present disposed to hold, the departure took place through the aid of language coincident with, or subsequent to, the human phase of evolution; cr whether, as other observers and thinkers believe, it took place, or is now taking place, in the lower mammalia or in other animals, is a matter for calm, temperate, and impartial discussion founded on accurate, and, as far as possible, crucial experiment and observation.

C. Lloyd MORGaN.

\section{Rules of Nomenclature.}

In your review of Mr. Massee's monograph of the Myxogastres (NATURE, p. ${ }^{6} 65$ ) I notice the sentence, "Under the generally accepted iules of nomenclature, this leads to Massee standing as the authority for many species, transferred by him, in reality, to another genus." I take this to mean tbat, for example, a species of which the trivial name is, say, abii, and which was originally described by an author Xyz, and referred (erroneously) by him to the genus Cdia, has been transferred now to another (the correct, according to present knowledge) genus Efia, and the name is now printed in this work not as Efia abii, Xyz, but as Efia abii, Massee. I am aware that this course is frequently adopted, but surely not " under the generally accepted rules of nomenclature." There is no copy of the British Association "Rules" within reach here, but my recollection is that they 